In Britain, thanks to the detailed description of the university system provided by documents such as the Robbins Report, there are good foundations for calculating how many people must be employed on science faculties at universities. For example, with an undergraduate population similar to that in 1964 , and on the assumption that one undergraduate in three stays on to do research, it is easy to conclude that university research in Britain should cost something like $£ 130$ million a year, at least on the assumption that each member of a scientific faculty costs roughly $£ 10,000$ a year by the time he has been provided with a salary, somewhere to work and with adequate assistance and materials. As it happens, this figure is not very different from that which the British Government at present spends on university research, either through the grants of the research councils or by the subventions of the University Grants Committee. The immediate interest, however, is that this line of argument could in principle be made to yield a link between the nation's demand on the educational system and the cost of scientific research in the universities. It would in particular show that the greatest cost in increasing the population of postgraduate students will be that of providing the students and those who teach them with opportunities for research.

Another yardstick could in principle be designed to ensure that a nation could hold on to a certain proportion of its senior scientists. Though not enough is known about the reasons why people leave nations in Western Europe to take permanent jobs in the United States for example, there is no question that one of the decisive factors is the availability of facilities for research. It follows that a nation wishing to keep a greater proportion of its skilled people at home must spend more on competitive facilities. With persistence, this line of argument could be made to yield criteria for deciding how much money should be spent on capital equipment of various kinds. Like the educational yardsticks, those based on attempts to prevent emigration at a certain level would necessarily be incomplete. They would, however, have the advantage of being ways of linking the cost of scientific research with tangible decisions about public policy in a wider field. At a time when the gross yardsticks based on Gross National Product are evidently too crude, and when treasuries everywhere are anxious to see further growth of science justified objectively, they obviously have great value.

\section{ELDO RECONSTITUTED}

THE new agreement on ELDO (European Launcher Development Organization) reached at Paris on July 8 seems to have papered over the cracks previously apparent in the structure of that organization, at least so far as the members are concerned. At the same time, the reputation of the British Government has been saved because the new agreement, operative from January 1, 1967, ensures that the British share of the cost will amount to 27 per cent, or just about two-thirds of the original levy. The fact that the West German contribution will, in future, be the same should further help to make it appear as if the Government has been fighting for nothing but the interests of its taxpayers in the past few months. In reality, however, the so-called apogee-perigee system to which British representatives were objecting vigorously on grounds of cost only a few months ago is now firmly written into an extended programme that will run until 1970.

The heads of the agreement at Paris include a determination to extend the ELDO programme so as to make possible a stationary communications satellite system of the kind proposed by the European Conference on Satellite Communications (CETS). On to the original ELDO- $A$ programme are to be grafted a number of subsidiary programmes, including some work on inertial guidance, the development of a launching site near the Equator in French Guiana (which has done little to comfort the Australians), and the development of two rocket systems to be fired at the perigee and then the apogee of an elliptical orbit so as to carry a load of as much as 200 kilograms into a stationary orbit about the Earth. It is expected that the cost of the four years of work from January 1967 will amount to 330 million dollars, or rather more than the sum that will have been spent by the end of 1966. By way of a watchdog, ELDO is to be provided with a force of financial inspectors. The central organization will in future be free to place contracts directly with potential contractors, but will have to suffer more frequent meetings of its controlling committees.

To the extent that an efficiently managed programme is better than one that is muddled, the last of this reorganization of ELDO is obviously something of a gain. Yet the suspicion remains that ELDO is awkwardly incomplete and inadequately constructed. For one thing, there is no guarantee and only a small likelihood of a commercial demand in 1970 for the kinds of communications satellites that ELDO will then be able to construct. And whatever successes the years ahead may bring, much more will be determined by what happens within the COMSAT organization in the United States, and in the development of its international links with other nations. In this sense, there is much in the view that the best insurance of European freedom in international telecommunications will be to drive tough bargains on landing rights from communications satellites-not to follow the American development of communications satellites proper. This is probably too cynical an argument, and may be wrong as well, but it would be a great mistake if the new excitement about ELDO were to blind its sponsors to the need for working out practical but permanent arrangements for European participation in international satellite communications, if necessary without the participation of European rockets. 